Research Article

\title{
Research of Joining Brittle Nonmetallic Materials with an Active Solder
}

\author{
Roman Koleňák and Michal Prach \\ Faculty of Materials Science and Technology in Trnava, Slovak University of Technology in Bratislava, \\ Paulinska 16, 91724 Trnava, Slovakia \\ Correspondence should be addressed to Michal Prach; michal.prach@stuba.sk
}

Received 29 September 2014; Revised 8 December 2014; Accepted 8 December 2014; Published 22 December 2014

Academic Editor: Dachamir Hotza

Copyright (c) 2014 R. Koleňák and M. Prach. This is an open access article distributed under the Creative Commons Attribution License, which permits unrestricted use, distribution, and reproduction in any medium, provided the original work is properly cited.

\begin{abstract}
This paper deals with soldering high-purity brittle, nonmetallic materials such as $\mathrm{SiO}_{2}, \mathrm{Si}$, and $\mathrm{C}$ (graphite). However, these materials exert poor wettability when using tin solder. Therefore, to reduce the wetting angle, an Sn solder alloyed with active Ti element was used. At a soldering temperature of $860^{\circ} \mathrm{C}$ and 15 min soldering time, the wetting angle on $\mathrm{SiO}_{2}$ ceramics was $30^{\circ}$, on silicon $42^{\circ}$, and on graphite $52^{\circ}$. All these wetting angles are below $90^{\circ}$ and are acceptable for soldering. It has been shown that the bond in all joined materials $\left(\mathrm{SiO}_{2}, \mathrm{Si}\right.$, and $\left.\mathrm{C}\right)$ was of a diffusion character. New intermetallic products were formed on the boundary with nonmetal, thus allowing bond formation. The shear strength of $\mathrm{SiO}_{2}$ ceramics attained an average value of $17 \mathrm{MPa}$.
\end{abstract}

\section{Introduction}

For diverse applications, mainly in electronics, we encountered problems with joining nonmetallic and ceramic materials [1-6]. Nowadays soldering offers an alternative method for the fabrication of joints in metallic as well as nonmetallic and ceramic materials.

Fabrication of a sound joint for nonmetallic materials with metallic solder depends on attaining close contact at an atomic distance with the contact surface and whether the metallic solder properly wets the nonmetallic material [7-10]. Wetting nonmetallic materials with metallic solder is a basic precondition for sound joint formation. Moreover, it is also required that the wetting angle in soldering be lower than $90^{\circ}$ [11-14]. A sound joint cannot otherwise be assured.

Wettability of nonmetallic materials was the subject of several research works. For example, in [15], the authors studied wetting diamond with pure liquid tin in a shielding atmosphere at temperatures from 500 to $1500^{\circ} \mathrm{C}$. Wetting angles of $\mathrm{Sn}$ on diamond substrate were within the range from 118 to $160^{\circ}$, which is unacceptable for soldering. Comparative wettability measurements of pure tin were also made by the authors on graphite, where a wetting angle of $155^{\circ}$ was measured at a temperature of $1477^{\circ} \mathrm{C}$.
Another study [16] dealt with wettability of $\mathrm{SiO}_{2}$ ceramics with nonactive metals such as $\mathrm{Au}, \mathrm{Si}$, and $\mathrm{Pb}$. The measured wetting angle for $\mathrm{Au}$ was $143^{\circ}\left(1080^{\circ} \mathrm{C}\right)$, Si was $87^{\circ}\left(1450^{\circ} \mathrm{C}\right)$, and $\mathrm{Pb}$ attained $120^{\circ}\left(727^{\circ} \mathrm{C}\right)$. A wetting angle of $87^{\circ}$ represents the limit of wettability in soldering. It was found that the bond between solders and substrate is created by Van der Waals forces that represent lower joint strength. However, joint strength is not the subject of this study. Wettability of graphite substrate with liquid Ag-Sn alloy was also studied at temperature intervals from 1000 to $1200^{\circ} \mathrm{C}$ [17]. The wetting angles were within a range of 125 to $142^{\circ}$.

Thus to ensure the wettability of nonmetallic material and lower the wetting angle, soldering must be done using solder alloyed with an active element [18-22]. Titanium and zirconium are mostly used as the active element [23]. The paper [24] was devoted to the wettability of Si-Al-O-N ceramics with $\mathrm{Sn}$ based solders and the addition of different active elements. The $\mathrm{Sn}-\mathrm{Ti}, \mathrm{Sn}-\mathrm{Hf}, \mathrm{Sn}-\mathrm{Zr}$, and $\mathrm{Sn}-\mathrm{V}$ soldering alloys were used, achieving wetting angles below $90^{\circ}$. The best results were achieved with $\mathrm{Sn}$-Ti solder, where the wetting angle at temperature $827^{\circ} \mathrm{C}$ was $25^{\circ}$, which is comparable with wettability on metallic materials. The authors' reason for this fact is that the lower the solubility of Ti in the alloy, the higher the activity of $\mathrm{Ti}$ in the liquid alloy. 
TABLE 1: Selected physical properties of ceramic, nonmetallic, and metallic materials [28].

\begin{tabular}{lcccc}
\hline Material/properties & $\mathrm{SiO}_{2}$ & $\mathrm{C}$ & $\mathrm{Si}$ & AISI 321 \\
\hline Melting point $\left[{ }^{\circ} \mathrm{C}\right]$ & 1710 & 3650 & 1414 & $1400-1425$ \\
Density $\left[\mathrm{g} \cdot \mathrm{cm}^{-3}\right]$ & 2.19 & 2.26 & 2.33 & 7.9 \\
Thermal expansivity coefficient & 0.54 & $0.6-4.3$ & 2.49 & 18.0 \\
{$\left[10^{-6} \mathrm{~K}^{-1}\right]$} & 69 & 6.9 & 112.4 & $190-210$ \\
Young's modulus [GPa] & 110 & 28 & - & $>560$ \\
Tensile strength [MPa] & & & & \\
\hline
\end{tabular}

In [25] the silicon substrate was soldered with active solder type $\mathrm{Sn}-\mathrm{Ag}-\mathrm{Ti}(\mathrm{Ce})$. Bond formation between $\mathrm{Si}$ and active solder was proven. Bond formation is attributable to the migration of active element on the solder boundary with silicon, resulting in a chemical reaction and formation of an interphase layer containing an oxide of the active element. The strength of the fabricated Si/Si joint was $6.67 \mathrm{MPa}$.

Wetting and interaction of $\mathrm{Sn}$-Ag-Ti solder on $\mathrm{Al}_{2} \mathrm{O}_{3}$ and $\mathrm{SiC}$ ceramic substrates were studied in [14]. We found that the contact angle of solder on ceramic material is lowered by increased temperature. Better wettability was achieved on $\mathrm{SiC}$ ceramics than $\mathrm{Al}_{2} \mathrm{O}_{3}$ due to a stronger interaction of solder with the surface of $\mathrm{SiC}$ ceramics. The wetting angle on $\mathrm{Al}_{2} \mathrm{O}_{3}$ ceramics was $40^{\circ}$ and on $\mathrm{SiC}$ ceramics it was almost $0^{\circ}$ at $700^{\circ} \mathrm{C} / 60 \mathrm{~min}$. It was also found that at $300^{\circ} \mathrm{C}$ the solder studied became molten but did not wet the ceramics surface. Surface tension forces the droplet to form into an ellipse. By subsequent heating above $700^{\circ} \mathrm{C}$, the solder wets both ceramic substrates and the final joint is thus attained.

In [26] the authors joined C/C composite (C/C NS 31 are silicon doped composites: Si 8-10 at. \%) with brazing alloy type Ti15Cu15Ni. The presence of Ti guaranteed wetting and adhesion of the substrate. The average shear strength of the joint was $24 \mathrm{MPa}$.

The authors of study [27] observed the formation of a $\mathrm{TiC}$ reaction product on the joint boundary of graphite substrate and brazing alloy type Ti30Zr15Cu10Ni. Active titanium from the brazing alloy created a bond with the graphite substrate. Increased temperature supports $\mathrm{Ti}$ diffusion and thus its concentration on the joint boundary, subsequently resulting in bond formation. The formation of an intermetallic compound is attributed to the interdiffusion of metallic elements.

In our work we dealt with soldering high-purity, brittle, nonmetallic materials such as $\mathrm{SiO}_{2}, \mathrm{Si}$, and $\mathrm{C}$. To reduce the wetting angle, $\mathrm{Sn}$ solder alloyed with active Ti element was used. From the literature survey it is obvious that the wettability of Sn-Ti based solders and mechanisms of joint formation in soldering $\mathrm{SiO}_{2}, \mathrm{Si}$, and $\mathrm{C}$ materials have not yet been the subject of previous studies. The capability of the SnTi alloy to create a sound joint was also studied.

AISI 321 steel was studied to compare results from wettability and shear strength tests. Metallic materials generally exert good wettability and solderability when compared with nonmetallic and ceramic materials. AISI 321 steel served as a reference metallic material.

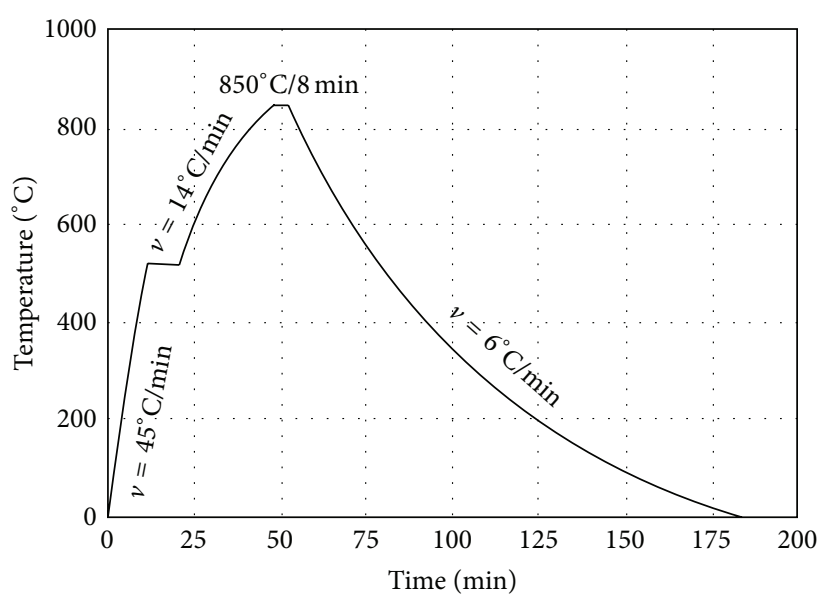

FIgURE 1: Thermal cycle course of vacuum soldering.

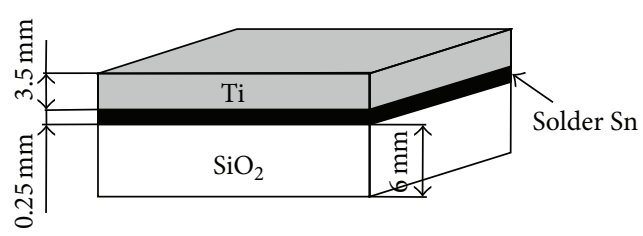

FIGURE 2: Arrangement of materials at soldering $\mathrm{SiO}_{2}$.

\section{Experimental}

Experiments were oriented toward the soldering of highpurity nonmetallic materials such as $\mathrm{SiO}_{2}, \mathrm{Si}$, and $\mathrm{C}$. The $\mathrm{SiO}_{2}$ ceramic substrate was of $4 \mathrm{~N} 5$ purity degree (99.995\%); graphite and silicon were of $5 \mathrm{~N}$ purity. Selected properties of substrates used are given in Table 1.

In the first case, nonactive 100Sn solder was used. The purity of this solder was $4 \mathrm{~N}$. Solder was enriched during the soldering process by an active element because one of the soldered parts was made of titanium with $99.95 \%$ purity.

In the second case, Sn3Ti solder was used for soldering. This solder was prepared by melting Sn with an appropriate amount of $\mathrm{Ti}$ at $950^{\circ} \mathrm{C}$ temperature in a vacuum.

Soldered joints were fabricated in a type PZ 810 electric resistance vacuum furnace in $10^{-2} \mathrm{~Pa}$ vacuum. This was applied owing to the high affinity of the active Ti element to oxygen, nitrogen, and hydrogen at higher temperatures. Soldering procedures consisted of inserting the appropriate solder between the joined parts, which were fixed in order to prevent mutual shift. The thermal profile of vacuum furnace soldering is documented in Figure 1. The scheme of experimental specimen is shown in Figure 2.

Specimens were cut after soldering and prepared by a standard metallographic procedure of grinding on SiC emery papers, polishing with diamond pastes with 6,3 , and $1 \mu \mathrm{m}$ granularity, and chemical polishing with Struers emulsion. The prepared samples were observed in the polished and etched condition by a NEOPHOT 30 type optical microscope. The etched samples were observed on scanning electron 


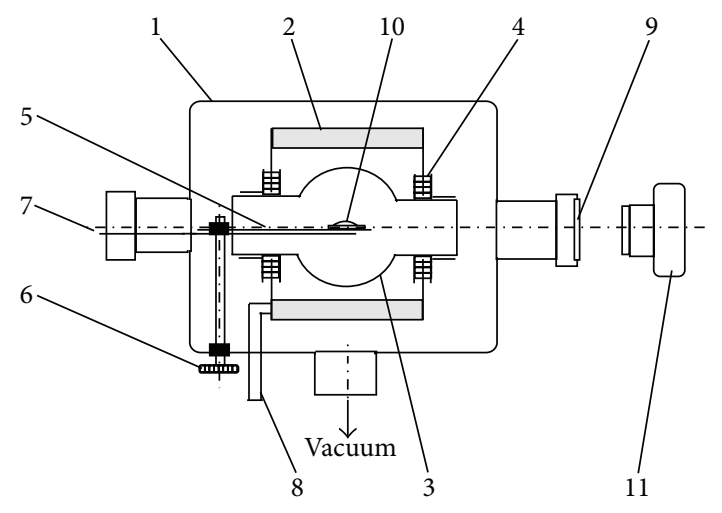
(1) Vacuum bell
(2) Cooling body of the oven
(7) Thermocouple
(3) Graphite oven
(4) Fastening ceramic pins
(8) Inlet and outlet of cooling water
(9) Observation hole for photography
(5) Feeder
(10) Specimen
(6) Feeder controller
(11) Photo camera

FIGURE 3: Schematic representation of apparatus for wettability measurement.

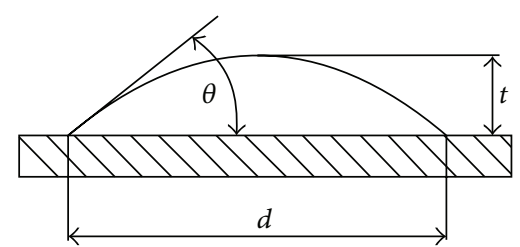

FIgURE 4: Profile of the molten metal drop laying on the support.

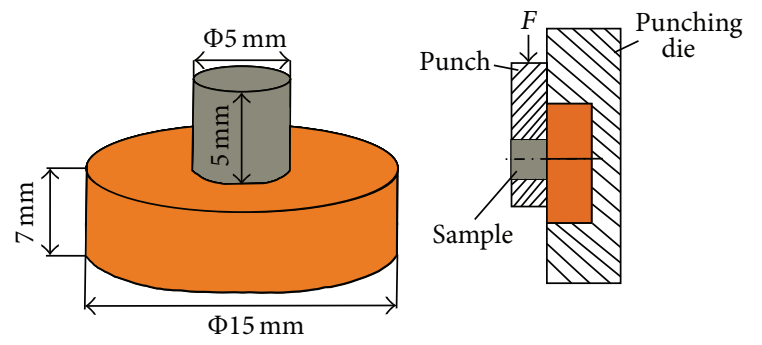

Figure 5: Test specimen for shear tests and the scheme of specimen in a jig during the shear test.

microscope type FEI Quanta 200 FEG and JEOL $7600 \mathrm{~F}$ with $\mathrm{X}$-ray microanalyser type Microspec WDX-3PC for performing the qualitative and semiquantitative chemical analysis. Xray diffraction analysis was applied for identification of phase composition by use of Philips PW 1710 equipment.

Wettability measurement of Sn3Ti solder was performed by use of the goniometric method, where the wettability is assessed by the value of wetting angle. The principle of the goniometric method consists of melting of a certain amount of active solder on the appropriate substrate in a vacuum furnace (Figure 3 ). The registration device is a camera with telephoto lens, by which the specimen is photographed through observation hole of the vacuum bell at preset temperatures. The wetting angle $(\Theta)$ is calculated from the parameters of

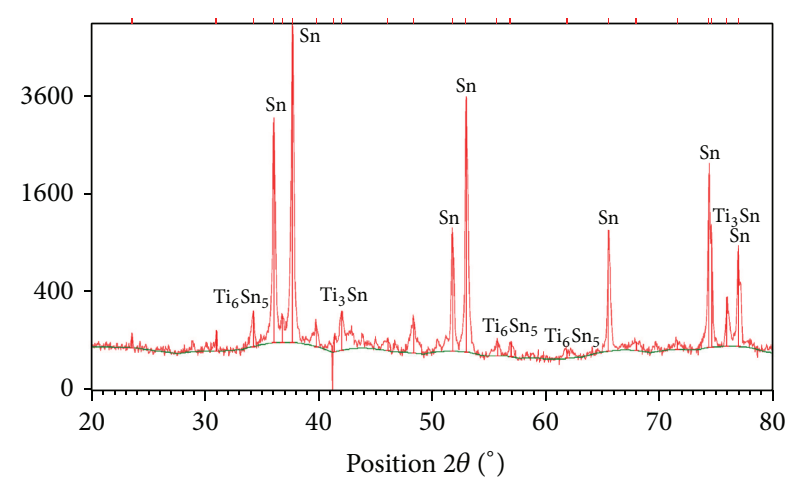

FIGURE 6: Diffraction record of Sn-Ti alloy.

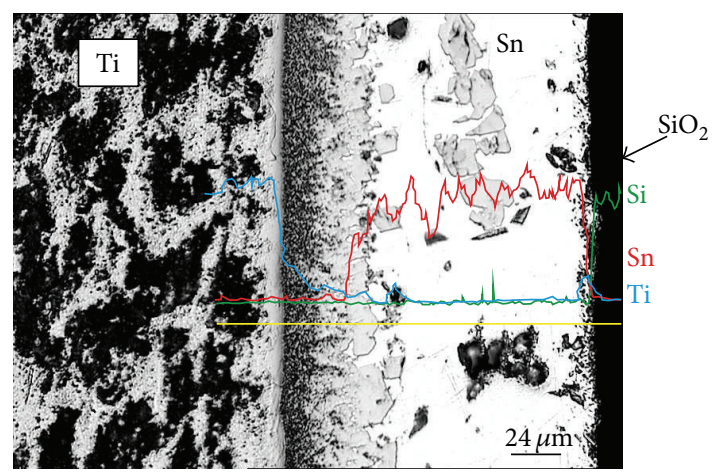

Figure 7: Microstructure of $\mathrm{Ti} / 100 \mathrm{Sn}$ solder $/ \mathrm{SiO}_{2}$ joint and the concentration profiles of $\mathrm{Si}, \mathrm{Sn}$, and $\mathrm{Ti}$ elements across the joint boundary.

solder drop $(t, d)$ measured on the snap taken by the camera-Figure 4 . The specimen was photographed at set regular time intervals $(0,5,10,15$, and $20 \mathrm{~min})$ and after assessment, the time dependence of wetting angle size was plotted.

Shear strength was tested on type LabTest 5.250SP1-VM equipment at room temperature. A shearing jig was used for the directional change in axial loading force on the test specimen. This jig ensures a uniform loading of the specimen by shear in the plane of solder and parent metal boundaryFigure 5. The shear gap was selected to $0.1 \mathrm{~mm}$.

\section{Experimental Results}

3.1. Analysis of $\mathrm{SiO}_{2} / 100 \mathrm{Sn}$ Solder/Ti Substrate Joint. Figure 7 shows the microstructure of the $\mathrm{Ti} / 100 \mathrm{Sn}$ solder $/ \mathrm{SiO}_{2}$ joint. Analysis of the chemical composition of soldered joints shows that Ti substrate starts to dissolve in the solder at temperature $770^{\circ} \mathrm{C}$ and forms a distinct solubility zone in the solder, Figures 7 and 8 . The temperature of melting start $770^{\circ} \mathrm{C}$ was determined by the $\mathrm{Sn}$ wettability test on Ti substrate.

The tin matrix of the solder is enriched by 2 to 4 wt. \% Ti. EDX and XRD analyses mainly revealed the presence of $\mathrm{Ti}_{6} \mathrm{Sn}_{5}$ phase and to a lesser extent the $\mathrm{Ti}_{3} \mathrm{Sn}$ phase was also observed. Diffraction record is documented in Figure 6. 


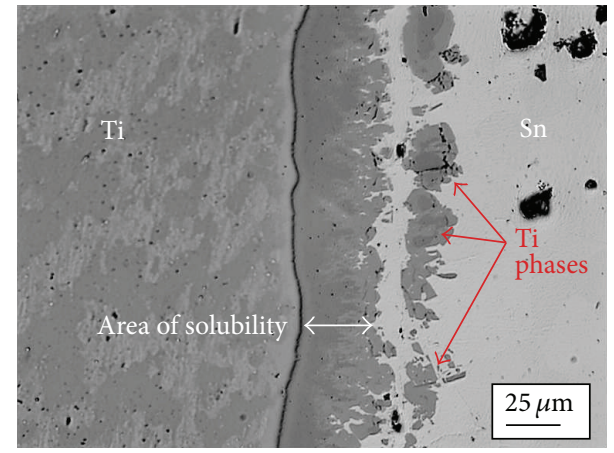

FIgUre 8: A detailed view on Ti substrate/100Sn solder boundary.

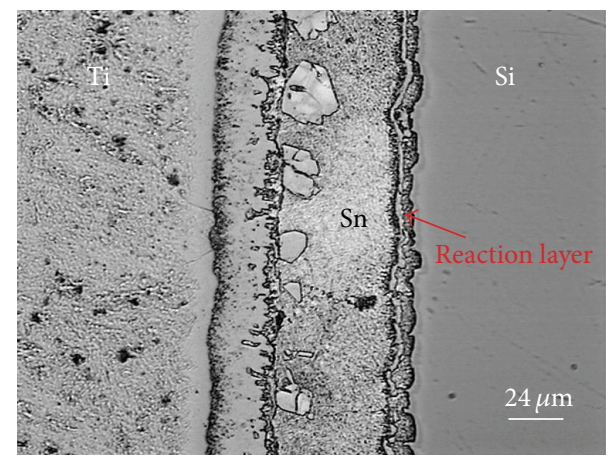

FIgURE 9: Etched boundary of Ti substrate/100Sn/Si solder.

The active titanium is further distributed to the boundary with ceramic $\mathrm{SiO}_{2}$ material. We determined its concentration on the solder $/ \mathrm{SiO}_{2}$ boundary (13.6 wt.\%). New reaction products are formed by a chemical reaction between active solder and the surface of the ceramic substrate. For example, $\mathrm{TiO}$ reaction product was identified there [29]. The reaction product forms the so-called reaction layer and thus ensures the wettability of ceramic material. The bond is of diffusion character.

A detailed view of $100 \mathrm{Sn}$ solder/Ti substrate boundary, with a solubility range of titanium in Sn solder, is shown in Figure 8. The band solubility zone of Ti in Sn solder may be observed, which attains an average $37 \mu \mathrm{m}$. Ti concentration in the solubility zone is 40 to $59 \mathrm{wt} . \% \mathrm{Ti}$, which corresponds to the composition of the $\mathrm{Ti}_{2} \mathrm{Sn}$ phase.

3.2. Analysis of Si/100Sn Solder/Ti Substrate Joint. Figure 9 shows the Ti/100Sn solder/Si boundary in etched condition. Using etchant $\left(1.5 \mathrm{~mL} \mathrm{HF}, 3 \mathrm{~mL} \mathrm{HNO}_{3}, 10 \mathrm{~mL} \mathrm{H} \mathrm{H}_{2} \mathrm{O}\right)$, emphasized titanium, which allows observation of the individual bordered zones in soldered joints (Figure 9).

The reaction layer of the $100 \mathrm{Sn}$ solder/Si substrate joint boundary (shown in Figure 10) has an average width $\sim 15 \mu \mathrm{m}$. This was formed by the interaction of activated titanium in the solder with the surface of Si substrate. The result of this mutual reaction is a product formed of Ti silicide. This $\mathrm{Ti}_{x} \mathrm{Si}_{y}$ reaction product is responsible for the bond formation

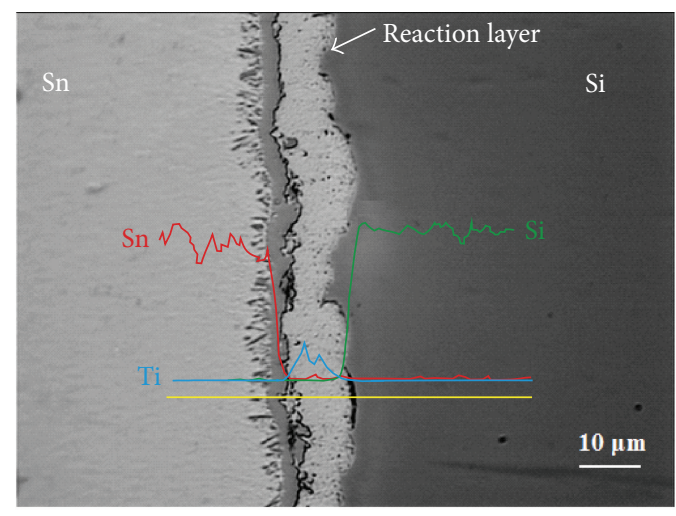

FIGURE 10: Reaction layer on 100Sn solder/Si substrate boundary and concentration profiles of $\mathrm{Si}, \mathrm{Sn}$, and Ti elements across the joint.

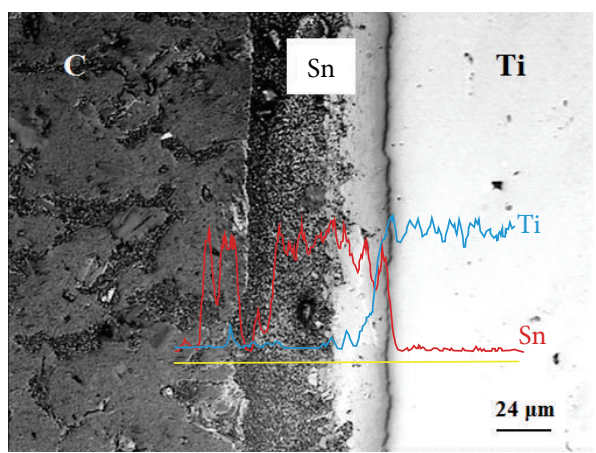

FIGURE 11: Microstructure of graphite (C)/100Sn solder/Ti substrate boundary and the concentration profiles of $\mathrm{Sn}$ and $\mathrm{Ti}$ elements across the joint boundary.

between $100 \mathrm{Sn}$ solder enriched by $\mathrm{Ti}$ and silicon substrate [29].

Concentration of these $\mathrm{Si}, \mathrm{Sn}$, and Ti elements across the boundary may be assessed by qualitative chemical analysisFigure 10. Increased Ti concentrations in the 100Sn solder/Si substrate boundary may be thus observed.

3.3. Analysis of C Graphite/100Sn Solder/Ti Substrate Joint. The microstructure of graphite/100Sn solder/Ti substrate joints after etching is shown in Figure 11. Concentration profiles were determined only for $\mathrm{Sn}$ and $\mathrm{Ti}$, since the energydispersion analyser on which the chemical analysis was performed does not allow detection of the carbon presence in the sample studied. However, from the Ti concentration profile, it is again evident that Ti shows slightly increased concentration on the solder/graphite boundary.

3.4. Mechanism of Joint Formation. From individual joint analyses, it becomes evident that the joint formation mechanism is identical in all three cases of soldered substrates: $\mathrm{SiO}_{2}$, $\mathrm{Si}$, and $\mathrm{C} / \mathrm{Ti}$. Three basic zones may be identified in the soldered joints (Figure 12):

(i) zone of Ti solubility in Sn solder, 


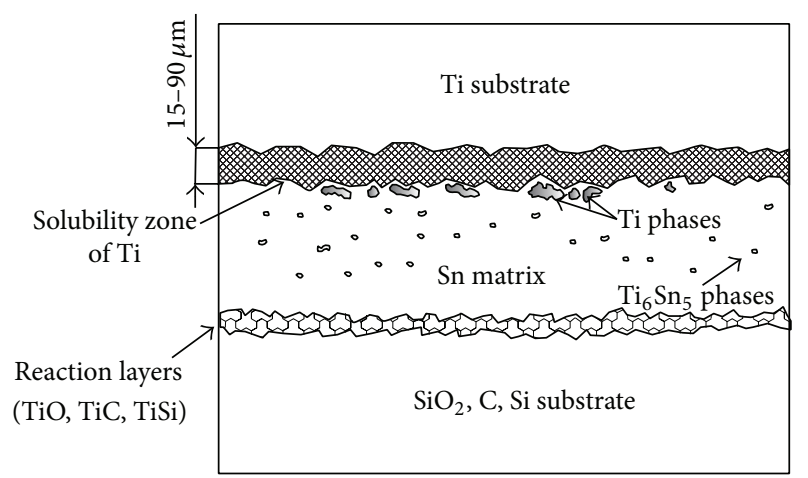

FIGURE 12: Scheme of individual zones in soldered joint.

(ii) solder matrix formed by tin grains with uniformly distributed $\mathrm{Ti}_{6} \mathrm{Sn}_{5}$ titanium phase (size of particles of $\mathrm{Ti}_{6} \mathrm{Sn}_{5}$ titanium phase is 10 to $25 \mu \mathrm{m}$ ),

(iii) reaction layer on the boundary with nonmetallic material.

The individual zones described are of different width. The greater amounts of $\mathrm{Ti}$ occurred in the $\mathrm{Ti}$ solubility zone in solder (40 to 59 wt.\%) and less Ti occurred in solder matrix ( 2 to $4 \mathrm{wt} . \%$ ). The titanium content in the reaction layer varies from 2.6 to $12 \mathrm{wt}$.\%. Schematic representations of individual zones in soldered joints are shown in Figure 12.

3.5. Wettability of Sn3Ti Solder. Based on the results, SnTi solder with 3 wt. $\%$ Ti was proposed. First of all, its wettability was determined on $\mathrm{SiO}_{2}$ ceramics and nonmetallic materials (Si and graphite).

Wettability tests on Sn3Ti solder were performed at a temperature of $860^{\circ} \mathrm{C}$. Wetting time varied within a range of $5,10,15$, and $20 \mathrm{~min}$.

In general, wettability on different materials was improved by longer wetting times, with the exception of silicon, where an opposite effect was observed-Figure 13.

On $\mathrm{SiO}_{2}$ ceramics, at a wetting time of $20 \mathrm{~min}$, a wetting angle of $26^{\circ}$ was observed. Observations on graphite at the same wetting time resulted in a $38^{\circ}$ wetting angle.

Stainless steel provided a reference material for comparisons of wettability. On stainless steel, using Sn3Ti solder, a wetting angle of $21^{\circ}$ was attained at 5 min wetting time. With longer wetting times, the wetting angle on AISI 321 steel improved only slightly-Figure 13.

Wettability tests for Sn3Ti solder were also applied to silicon and graphite. The effects of soldering temperatures on solderability were studied as well. In the case of graphite, the wetting temperature increased from $860^{\circ} \mathrm{C}$ to 900 and $950^{\circ} \mathrm{C}$. Wetting times varied within a range of $5,10,15$, and $20 \mathrm{~min}$. It was found that the wetting angle on graphite decreases with increased soldering temperatures-Figure 14. After reaching a temperature of $950^{\circ} \mathrm{C}$, the wetting angle was $118^{\circ}$. Within $20 \mathrm{~min}$ at a temperature $950^{\circ} \mathrm{C}$, the wetting angle gradually decreased to $23^{\circ}$, which is comparable with metallic materials.

In determining the wettability of Sn3Ti solder on silicon, an opposite effect was observed-Figure 15. The wetting angle

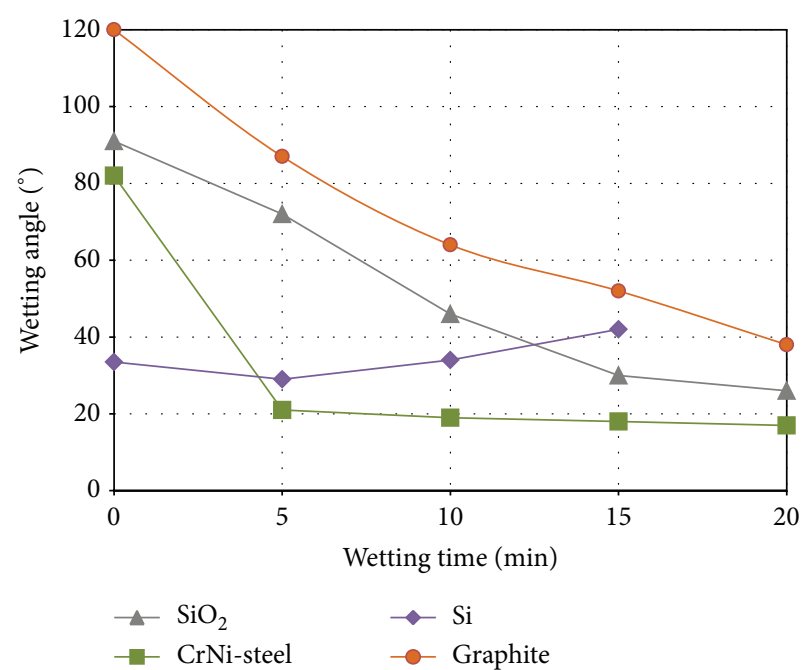

Figure 13: Dependence of wettability of Sn3Ti solder on $\mathrm{SiO}_{2}$, ceramics, stainless steel type AISI 321, and Si and graphite nonmetals at temperature $860^{\circ} \mathrm{C}$.

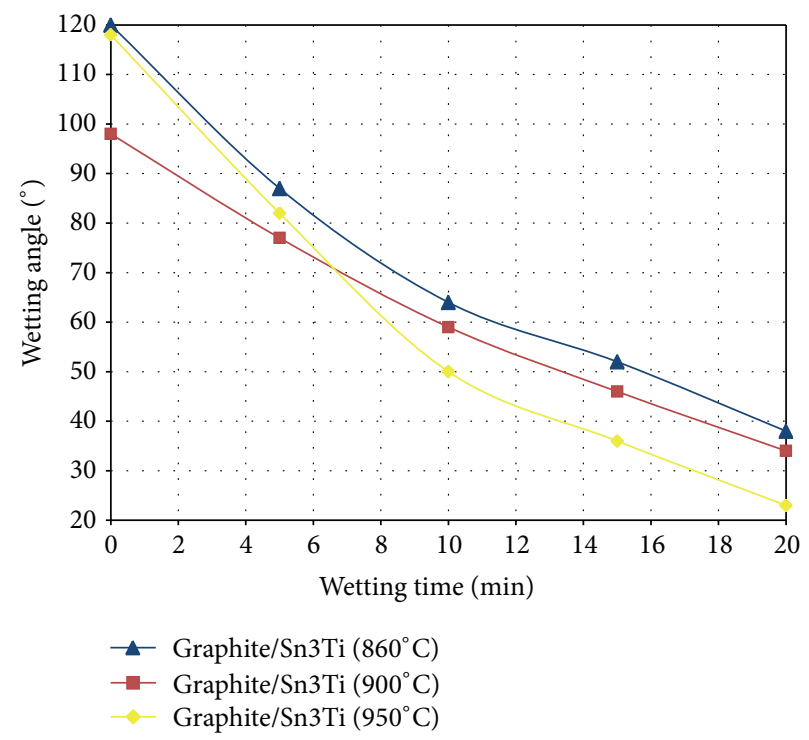

FIGURE 14: Wettability of Sn3Ti solder on graphite at temperatures 860,900 , and $950^{\circ} \mathrm{C}[21]$.

at $5 \mathrm{~min}$ and $800^{\circ} \mathrm{C}$ was $19^{\circ}$. During the dwell time at soldering temperature of $15 \mathrm{~min}$, the wetting angle increased to $22^{\circ}$. It became worse at $900^{\circ} \mathrm{C}$. At $15 \mathrm{~min}$ it increased from an initial $34^{\circ}$ to $61^{\circ}$. Analysis has shown that wetting angle is damaged due to the dissolution of silicon substrate and alloying of Sn3Ti solder with silicon [29].

The results of wettability tests of graphite and silicon revealed that, in the case of soldering graphite, it is more advisable to choose higher soldering temperatures and longer dwell times on soldering temperature. On the contrary, in cases of silicon, lower temperatures and shorter soldering times are necessary. In any case, a temperature of $800^{\circ} \mathrm{C}$ is the lower limit for the thermal activation of titanium in tin solder. 


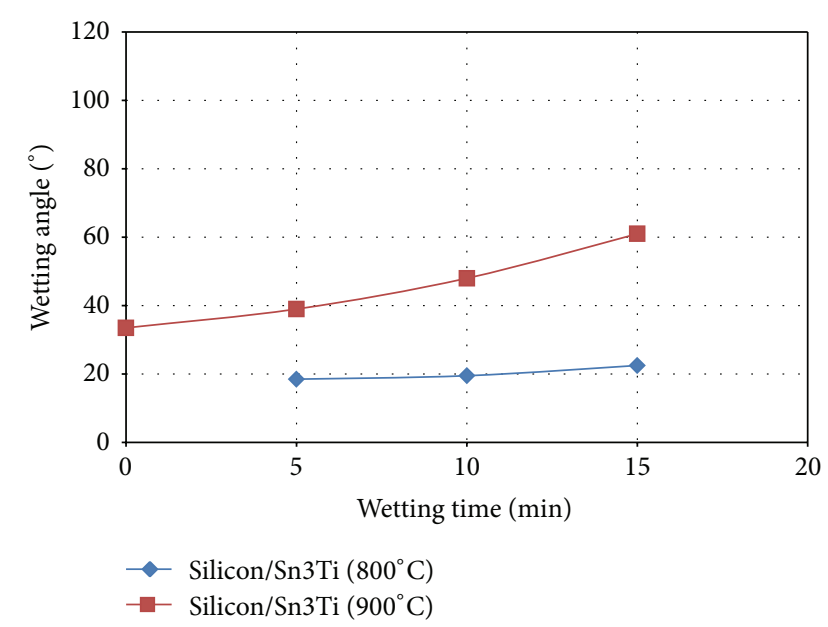

FIgURE 15: Wettability of Sn3Ti solder on silicon at temperatures $800^{\circ} \mathrm{C}$ and $900^{\circ} \mathrm{C}$.

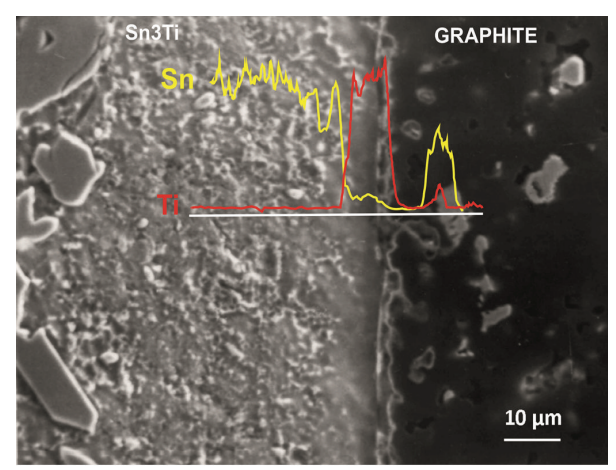

FIgUre 16: Concentration profile of Sn and Ti elements on Sn3Ti solder/graphite boundary [21].

3.6. Analysis of Soldered Joints Fabricated with Sn3Ti Solder. Figure 16 illustrates the microstructure of a graphite/SnTi3 solder joint and the concentration profile of $\mathrm{Sn}$ and $\mathrm{Ti}$ elements on the graphite/Sn3Ti solder boundary. The amount of active Ti element was determined by EDX analysis. Concentrations of active Ti element in the reaction layer on the graphite/solder boundary varied from 8.98 to $10.11 \mathrm{wt} . \%$. Planar analysis of the graphite/Sn3Ti solder boundary is shown in Figure 17. From this analysis it becomes evident that a maximum concentration of titanium occurred in the reaction layer of the graphite/Sn3Ti solder boundary. The solder is capable of penetrating to the full depth of the graphite substrate. The pores within graphite are filled with tin, with increasing amounts of Ti up to $10 \mathrm{wt} . \%$. This topic about soldering of graphite substrate was discuss detailed in the contribution [21].

Figure 18 illustrates the concentration profile of $\mathrm{Si}, \mathrm{Sn}$, and $\mathrm{Ti}$ elements on $\mathrm{SiO}_{2} / \mathrm{Sn} 3 \mathrm{Ti}$ solder boundaries. The amount of active Ti element was determined by EDX analysis. Concentrations of active $\mathrm{Ti}$ element in reaction layers on $\mathrm{SiO}_{2}$ /solder boundaries varied from 4.63 to $5.74 \mathrm{wt} . \%$ [30].

Figure 19 illustrates the microstructure of the Sn3Ti/silicon substrate joint. The active Ti reacted, as in previous cases,
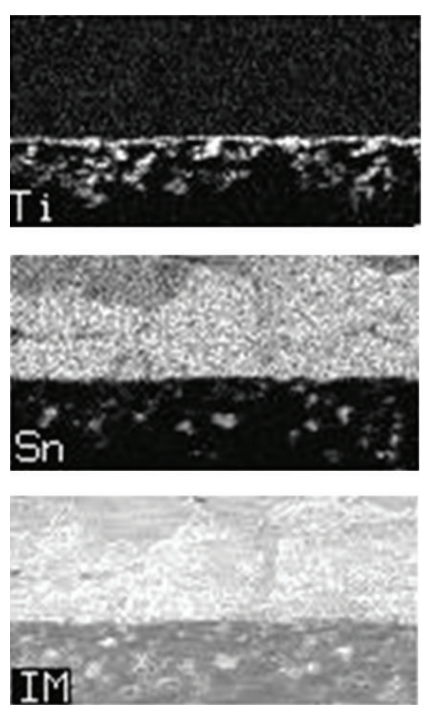

FIGURE 17: Planar distribution of elements on graphite/Sn3Ti solder boundary [21].

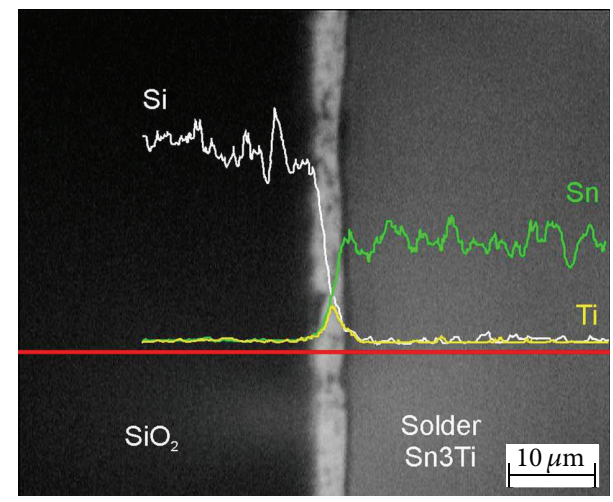

FIGURE 18: Concentration profile of $\mathrm{Si}, \mathrm{Sn}$, and Ti elements on $\mathrm{SiO}_{2} / \mathrm{Sn} 3 \mathrm{Ti}$ solder boundary [30].

with the surface of silicon substrate at reaction layer formation. The average thickness of this layer was around $4 \mu \mathrm{m}$ and contained from 5.52 to $7.43 \mathrm{wt}$ \% Ti.

3.7. Shear Strength of Joints. Test specimens of joints were fabricated with Sn3Ti solder by applying findings attained by the measurement of wetting angles. Results of shear strength tests are shown in Figure 20. In cases of soldering $\mathrm{SiO}_{2}$ ceramics using Sn3Ti solder, an average strength of $17 \mathrm{MPa}$ was achieved.

A higher shear strength of $21 \mathrm{MPa}$ was achieved by soldering stainless steel type AISI 321 joints using Sn3Ti solder.

3.8. Discussion of Results Achieved with Sn3Ti Solder. The results of solder wettability on ceramic and nonmetallic materials such as $\mathrm{SiO}_{2}, \mathrm{Si}$, and $\mathrm{C}$ (graphite) proved that $\mathrm{Sn}$ solder with Ti content significantly reduces the wetting angle; thus Sn3Ti solder is ideally suitable for practical soldering applications. Contrary to previous studies [15-17], we have achieved wetting angles below $90^{\circ}$. For example, in [16] we 


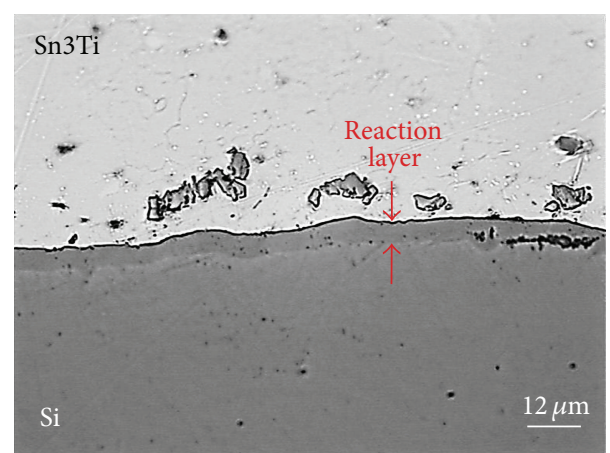

FIgURE 19: Microstructure of boundary of Si/Sn3Ti joint.

found that the nonactive $\mathrm{Au}, \mathrm{Si}$, and $\mathrm{Pb}$ metals wet $\mathrm{SiO}_{2}$ ceramics only with great wetting angles. For $\mathrm{Au}$ this was $143^{\circ}$ $\left(1080^{\circ} \mathrm{C}\right)$, for $\mathrm{Si}$ was $87^{\circ}\left(1450^{\circ} \mathrm{C}\right)$, and for $\mathrm{Pb}$ was $120^{\circ}\left(727^{\circ} \mathrm{C}\right)$. The measured wetting angle for pure tin in study [15] on graphite substrates was $155^{\circ}$ at a temperature of $1477^{\circ} \mathrm{C}$.

We observed that the wetting angle on $\mathrm{SiO}_{2}$ ceramics at a temperature of $860^{\circ} \mathrm{C}$ was $30^{\circ}$, with silicon $42^{\circ}$ and graphite $52^{\circ}$. These wetting angles are all well below $90^{\circ}$ and are therefore acceptable for soldering. However, tin alloyed with 3 wt.\% Ti was used in our case. The wettability achieved is comparable to that observed on metals. For example, the wetting angle achieved on AISI 321 steel, used as reference material, was $21^{\circ}$ at $860^{\circ} \mathrm{C}$.

Regarding the mechanism of joint formation, in applications of Sn3Ti solder and soldering temperatures above $800^{\circ} \mathrm{C}$, a joint formation of diffusion character with the formation of new reaction products was observed. The formation of a new $\mathrm{TiC}$ reaction product was also proven in [27], in the case of soldering a graphite substrate with $\mathrm{Ti}$ containing solder. To the contrary, in [16] we find that in cases of nonactive metals the bond between solders and substrate created by the Van der Waals forces produces great wetting angles. In [14] it was also proven that, at a temperature of $300^{\circ} \mathrm{C}$, solder type $\mathrm{Sn}-\mathrm{Ag}$-Ti fails to wet ceramic materials such as $\mathrm{Al}_{2} \mathrm{O}_{3}$ and $\mathrm{SiC}$. By subsequent heating above $700^{\circ} \mathrm{C}$, solder wets the ceramic substrate and the joint can be created.

By comparing results from measurements of shear strength, we also identify the results from similar studies, taking into account that different works make use of different test methods, shape of test specimens, and loading rates at testing. They also use different compositions of solders and soldering parameters. For example, in the case of the application of Sn4Ti solder in [31] in the joint of Ti/Ti metallic material, a shear strength of 16.5 MPa was attained. More studies [25, 3235] dealt with solder types $\mathrm{Sn}-\mathrm{Ag}$-Ti and $\mathrm{Sn}-\mathrm{Ag}-\mathrm{Ti}(\mathrm{Ce})$. They tested metallic, nonmetallic, and ceramic materials.

In study [32], the $\mathrm{Al} / \mathrm{Al}$ joint showed a shear strength of 15.3 $\mathrm{MPa}$. In [33], the following strengths were achieved by soldering: $\mathrm{Cu} / \mathrm{Cu}(14.3 \mathrm{MPa})$, ITO/ITO (6.8 MPa), and ITO/ $\mathrm{Cu}$ (3.4) MPa. Similarly in the study [34] the following shear strength values of joints were attained: $\mathrm{Cu} / \mathrm{Cu}(13.3 \mathrm{MPa})$ and $\mathrm{ZnS}-\mathrm{SiO}_{2} / \mathrm{ZnS}-\mathrm{SiO}_{2}(6.5 \mathrm{MPa})$. The fabricated $\mathrm{Si} / \mathrm{Si}$ joint [25] demonstrated a shear strength of $6.67 \mathrm{MPa}$. In our study, similar shear strength results were achieved.

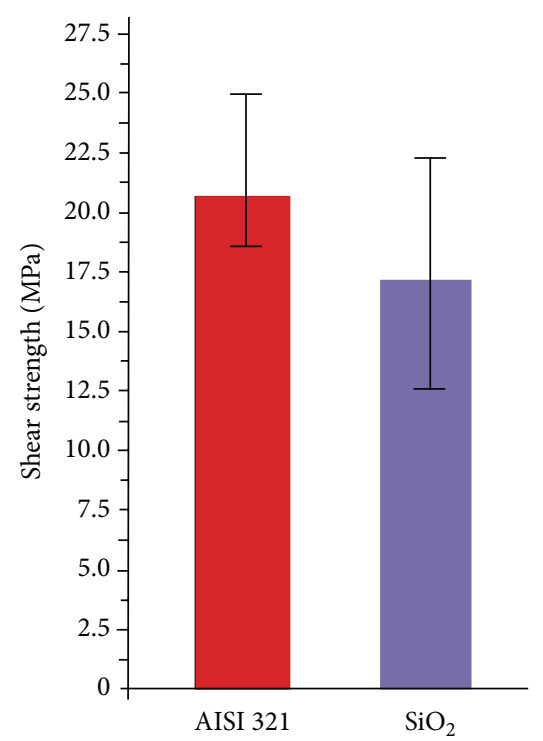

FIGURE 20: Shear strength of joints fabricated with Sn3Ti solder.

\section{Conclusions}

The aim of this research is to prove the reaction capacity and wettability of $\mathrm{Ti}$ containing solder on selected ceramic and nonmetallic materials to form a strong joint.

The following was discovered on the basis of experiments performed.

(i) Active Ti metal ensured good wetting of ceramic $\mathrm{SiO}_{2}$ materials as well as nonmetallic materials such as graphite and silicon.

(ii) The wettability of different materials was generally improved by longer wetting times; however, an opposite effect was observed with silicon-wettability deteriorated due to the dissolution of silicon substrate in liquid.

(iii) $\mathrm{On} \mathrm{SiO}_{2}$ ceramics at 20 min wetting time, a wetting angle of $26^{\circ}$ was observed. At an identical wetting time, the wetting angle on graphite was $38^{\circ}$ and $42^{\circ}$ on silicon.

(iv) In soldered joints of ceramic and nonmetallic materials with Ti substrate, three different basic zones may be identified:

(a) Ti solubility zone in tin solder,

(b) solder matrix formed of tin grains with a uniformly distributed $\mathrm{Ti}_{6} \mathrm{Sn}_{5}$ titanium phase,

(c) reaction layer on the boundary with nonmetallic materials.

(v) The individual zones identified were of varied width. The highest amount of Ti occurred in the Ti solubility zone in the solder (40 to $59 \mathrm{wt} . \%$ ) and lesser amounts in solder matrix ( 2 to 4 wt.\%). Titanium content in the reaction layer varied from 2.6 to $12 \mathrm{wt} . \%$.

(vi) The mechanism of joint formation in soldering with 100Sn solder is as follows: $\mathrm{Ti}$ substrate is dissolved 
in Sn solder. Active Ti metal is diffused through the solder matrix up to the boundary of the solder with the ceramic substrate, where it ensures wettability and strong bond formation by its interaction with the surfaces of ceramic and/or nonmetallic materials.

(vii) When soldering $\mathrm{SiO}_{2}$ ceramics using $\mathrm{Sn} 3 \mathrm{Ti}$ solder, an average strength of $17 \mathrm{MPa}$ was achieved. When soldering the joints of stainless steel with the same solder, a higher average shear strength was achieved, even up to $21 \mathrm{MPa}$.

The performed experiments justified the solution of intricate wettability of brittle ceramic and nonmetallic materials by using active Sn-based solders.

\section{Conflict of Interests}

The authors declare that there is no conflict of interests regarding the publication of this paper.

\section{Acknowledgments}

This research was supported by APVV-0023-12: research of new soldering alloys for fluxless soldering with application of beam technologies and ultrasound, and VEGA 1/0455/14: research of modified solders for fluxless soldering of metallic and ceramic materials. The authors' thanks belong to Mrs. Bachratá from U'MMS SAV Bratislava for performing the wettability measurements; Ing. Peter Žúbor, Ph.D., for metallographic analysis; Associate Professor Ing. Maroš Martinkovič, Ph.D., for providing the methodics for shear test measurement; Associate Professor Ing. Martin Kusý, Ph.D., for XRD analysis.

\section{References}

[1] A.-P. Xian, "Joining of sialon ceramics by $\mathrm{Sn}-5$ at \% Ti based ternary active solders," Journal of Materials Science, vol. 32, no. 23, pp. 6387-6393, 1997.

[2] M. Singh, G. N. Morscher, T. P. Shpargel, and R. Asthana, "Active metal brazing of titanium to high-conductivity carbon-based sandwich structures," Materials Science and Engineering A, vol. 498, no. 1-2, pp. 31-36, 2008.

[3] H. Ning, Z. Geng, J. Ma, F. Huang, Z. Qian, and Z. Han, "Joining of sapphire and hot pressed $\mathrm{Al}_{2} \mathrm{O}_{3}$ using $\mathrm{Ag}_{70.5} \mathrm{Cu}_{27.5} \mathrm{Ti}_{2}$ brazing filler metal," Ceramics International, vol. 29, no. 6, pp. 689-694, 2003.

[4] S. Y. Chang, Y. T. Hung, and T. H. Chuang, "Joining alumina to Inconel 600 and UMCo-50 superalloys using an Sn10Ag4Ti active filler metal," Journal of Materials Engineering and Performance, vol. 12, no. 2, pp. 123-127, 2003.

[5] W. R. Smith, "Active solder joining of metals ceramics and composites," Welding Journal, vol. 10, pp. 30-35, 2001.

[6] R. R. Kapoor and T. W. Eagar, "Tin-based reactive solders for ceramic/metal joints," Metallurgical Transactions B, vol. 20, no. 6, pp. 919-924, 1989.

[7] S. Y. Chang, T. H. Chuang, and C. L. Yang, "Low temperature bonding of alumina/alumina and alumina/copper in air using $\mathrm{Sn}_{3.5} \mathrm{Ag}_{4} \mathrm{Ti}(\mathrm{Ce}, \mathrm{Ga})$ filler," Journal of Electronic Materials, vol. 36, no. 9, pp. 1193-1198, 2007.
[8] R. R. Kapoor and T. W. Eagar, "Tin-based reactive solders for ceramic/metal joints," Metallurgical Transactions B, vol. 20, no. 6, pp. 919-924, 1989.

[9] O. M. Kostin, Al. V. Labartkava, and V. A. Martynenko, "Study of the interaction processes of Ti-containing solders with oxide ceramics and Kovar," Mettallofizika i Noveishie Tekhnologii, vol. 36, no. 6, pp. 815-827, 2014.

[10] P. Xiao and B. Derby, "Wetting of silicon carbide by chromium containing alloys," Acta Materialia, vol. 46, no. 10, pp. 34913499, 1998.

[11] H. Manko, Solders and Soldering, McGraw-Hill, 4th edition, 2011.

[12] F. Hillen, D. Pickart-Castillo, J. I. Rass, and E. Lugscheider, "Solder alloys and soldering processes for flux-free soldering of difficult to-wet materials," Welding \& Cutting, vol. 52, no. 8, pp. E162-E165, 2000.

[13] Y. V. Naidich, V. S. Zhuravlev, I. I. Gab et al., "Liquid metal wettability and advanced ceramic brazing," Journal of the European Ceramic Society, vol. 28, no. 4, pp. 717-728, 2008.

[14] Y. H. Chai, W. P. Weng, and T. H. Chuang, "Relationship between wettability and interfacial reaction for Sn10Ag4Ti on $\mathrm{Al}_{2} \mathrm{O}_{3}$ and $\mathrm{SiC}$ substrates," Ceramics International, vol. 24, no. 4, pp. 273-279, 1998.

[15] K. Nogi, M. Nishikawa, H. Fujii, and S. Hara, "Wettability of diamond by liquid pure tin," Acta Materialia, vol. 46, no. 7, pp. 2305-2311, 1998.

[16] R. Sangiorgi, M. L. Muolo, D. Chatain, and N. Eustathopoulos, "Wettability and work of adhesion of nonreactive liquid metals on silica," Journal of the American Ceramic Society, vol. 71, no. 9, pp. 742-748, 1988.

[17] Z. Weltsch, A. Lovas, J. Takács, Á. Cziráki, A. Toth, and G. Kaptay, "Measurement and modelling of the wettability of graphite by a silver-tin (Ag-Sn) liquid alloy," Applied Surface Science, vol. 268, pp. 52-60, 2013.

[18] R. Koleňák, P. Šebo, M. Provazník, M. Koleňáková, and K. Ulrich, "Shear strength and wettability of active $\mathrm{Sn}_{3.5} \mathrm{Ag}_{4} \mathrm{Ti}(\mathrm{Ce}$, Ga) solder on $\mathrm{Al}_{2} \mathrm{O}_{3}$ ceramics," Materials and Design, vol. 32, no. 7, pp. 3997-4003, 2011.

[19] S. Y. Chang, T. H. Chuang, and C. L. Yang, "Low temperature bonding of alumina/alumina and alumina/copper in air using Sn3.5Ag4Ti(Ce,Ga) filler," Journal of Electronic Materials, vol. 36, no. 9, pp. 1193-1198, 2007.

[20] R. Koleňák and M. Prach, "Research of soldering silicon substrate with solders type Sn-Ag-Ti," Metalurgia International, vol. 18, no. 8, pp. 260-264, 2013.

[21] R. Koleňák and M. Prach, "Research of joining graphite by use of active solder," Advanced Materials Research, vol. 875-877, pp. 1270-1274, 2014.

[22] K. Ferguson, "Active brazing joins titanium-graphite beam target for subatomic particle detection," Advanced Materials and Processes, vol. 170, no. 8, pp. 25-27, 2012.

[23] R. Koleňák and M. Prach, "Joining active metals with $\mathrm{Al}_{2} \mathrm{O}_{3}$ by use of solders," Advanced Materials Research, vol. 664, pp. 667671,2013

[24] A.-P. Xian and Z.-Y. Si, "Wetting of tin-based active solder on sialon ceramic," Journal of Materials Science Letters, vol. 10, no. 22, pp. 1315-1317, 1991.

[25] C. Peng, M. Chen, and S. Liu, "Die bonding of Silicon and other materials with active solder," in Proceedings of the International Conference on Electronic Packaging Technology and High Density Packaging, pp. 275-278, 2010. 
[26] P. Appendino, V. Casalegno, M. Ferraris, M. Grattarola, M. Merola, and M. Salvo, "Joining of C/C composites to copper," Fusion Engineering and Design, vol. 66-68, pp. 225-229, 2003.

[27] Z. Zhong, Z. Zhou, and C. Ge, "Brazing of doped graphite to $\mathrm{Cu}$ using stress relief interlayers," Journal of Materials Processing Technology, vol. 209, no. 5, pp. 2662-2670, 2009.

[28] Material Properties Charts, CoorsTek, Inc., http://www.coorstek.com/.

[29] R. Koleňák, Solderability of metallic and ceramic materials by active solders [Habilitation thesis], Slovenská Technická Univerzita, Trnava, Slovakia, 2006.

[30] R. Koleňák and M. Chachula, "Research of joining $\mathrm{SiO}_{2}$ ceramic material by use of active solder," Advanced Science Letters, vol. 19, no. 2, pp. 406-410, 2013.

[31] L. C. Tsao, "Direct active soldering of micro-arc oxidized Ti/Ti joints in air using Sn3.5Ag0.5Cu4Ti(RE) filler," Materials Science and Engineering A, vol. 565, pp. 63-71, 2013.

[32] L. C. Tsao, "Interfacial structure and fracture behavior of 6061 $\mathrm{Al}$ and MAO-6061 Al direct active soldered with Sn-Ag-Ti active solder," Materials and Design, vol. 56, pp. 318-324, 2014.

[33] S. Y. Chang, L. C. Tsao, M. J. Chiang, C. N. Tung, G. H. Pan, and T. H. Chuang, "Active soldering of indium tin oxide (ITO) with $\mathrm{Cu}$ in air using an $\mathrm{Sn}_{3.5} \mathrm{Ag}_{4} \mathrm{Ti}(\mathrm{Ce}, \mathrm{Ga})$ filler," Journal of Materials Engineering and Performance, vol. 12, no. 4, pp. 383-389, 2003.

[34] S. Y. Chang, "Active soldering of $\mathrm{ZnS}-\mathrm{SiO}_{2}$ sputtering targets to copper backing plates using an $\operatorname{Sn} 56 \mathrm{Bi} 4 \mathrm{Ti}(\mathrm{Ce}, \mathrm{Ga})$ filler," Materials and Manufacturing Processes, vol. 21, no. 8, pp. 761-765, 2006.

[35] I. Hlavatý, "Solderability of high-purity aluminium with the lead-free tin solders," in Proceedings of the 22st International DAAAM Symposium "Intelligent Manufacturing and Automation", vol. 22 of Annals of DAAAM, pp. 818-819, Vienna, Austria, 2011. 

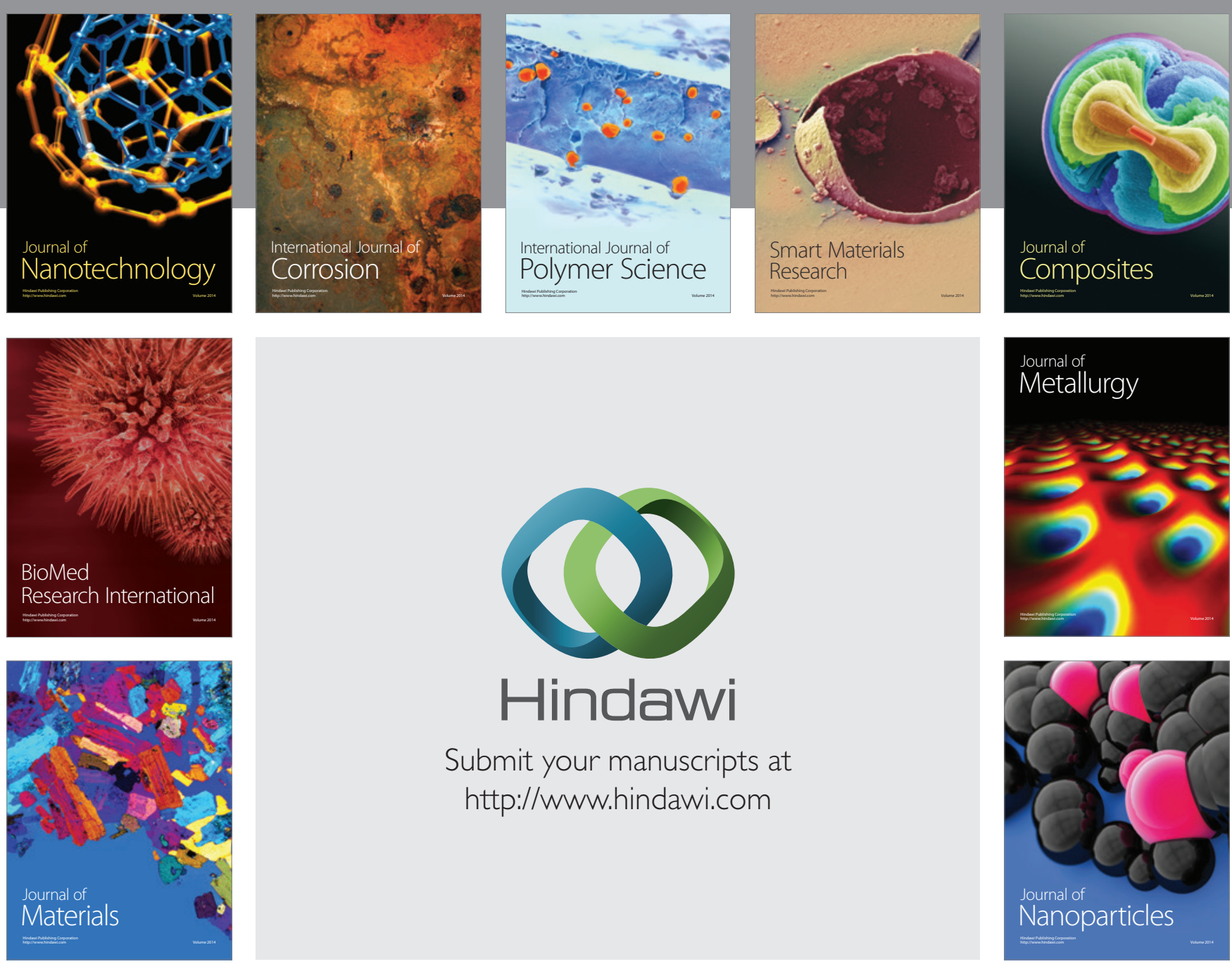

Submit your manuscripts at http://www.hindawi.com
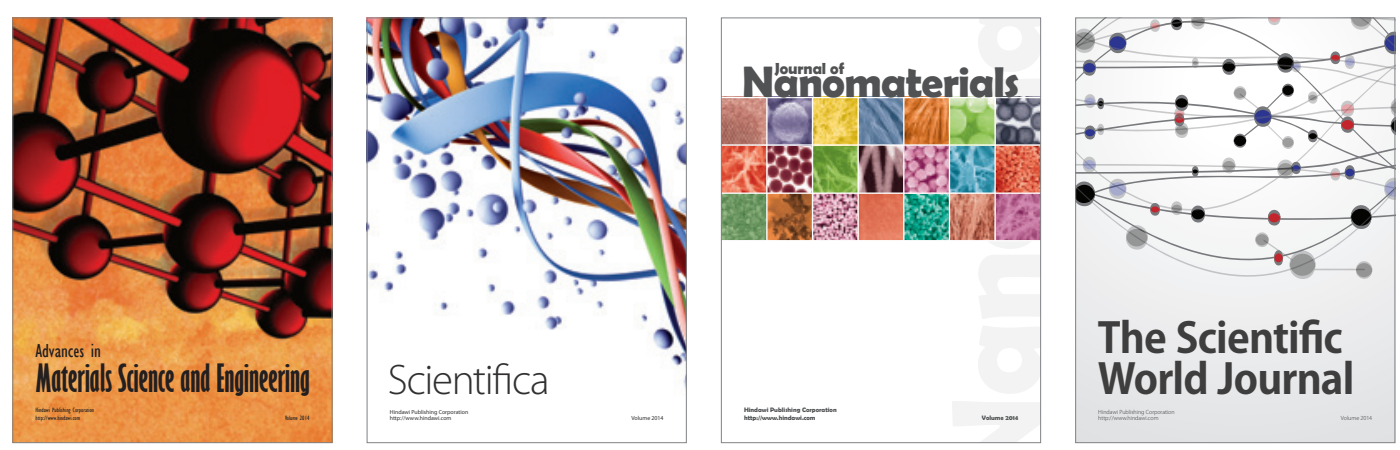

\section{The Scientific World Journal}
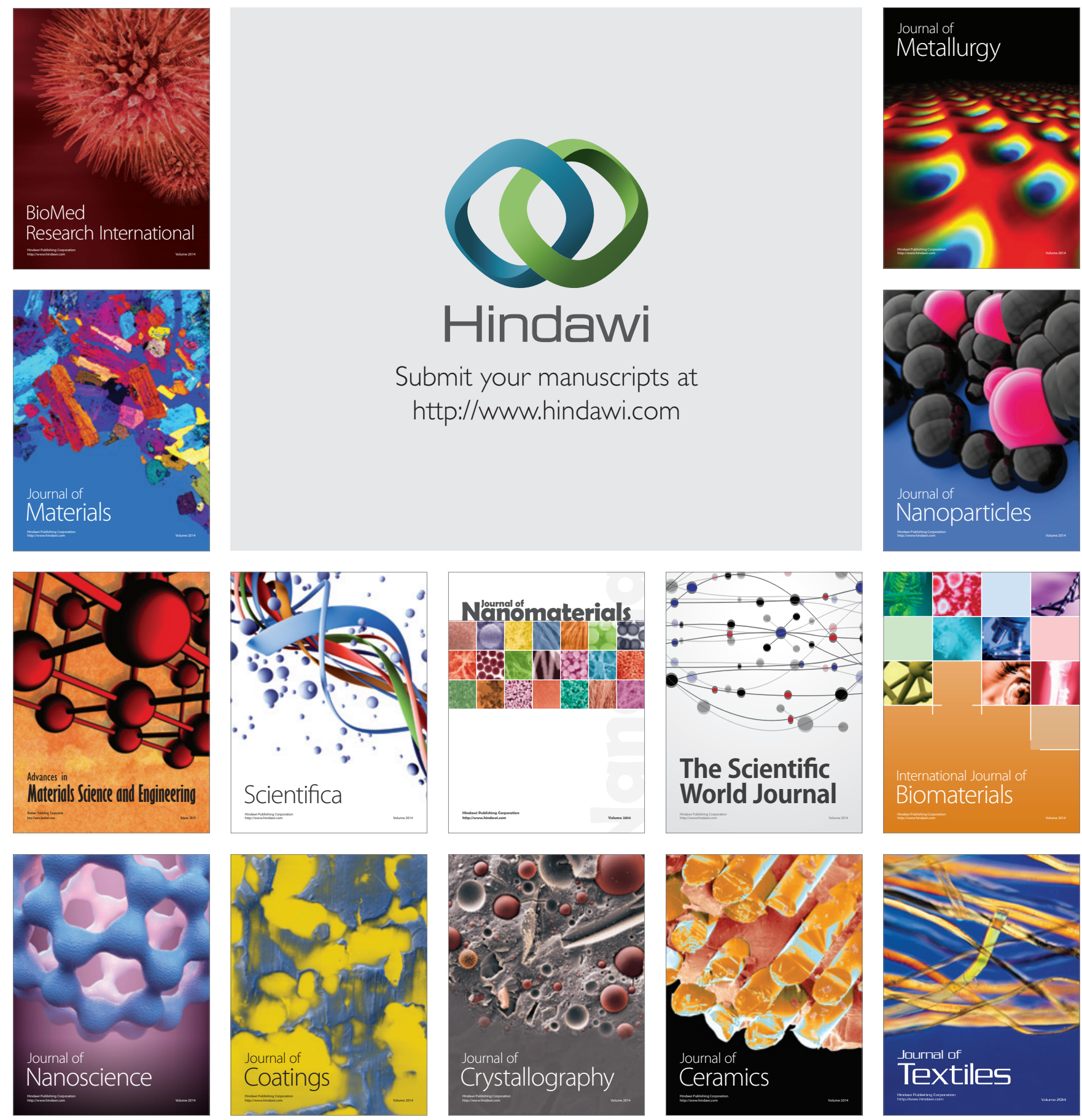